\title{
20
}

\section{Measuring and re-engineering logistics chains in the construction industry}

\author{
T. Wegelius-Lehtonen \\ Helsinki University of Technology, IIA Research center \\ Otakaari 4A, FIN-02150 Espoo, Finland \\ Tel. 358-0-451 3664, Fax. 358-0-451 3665 \\ E-Mail: Tutu.Wegelius@hut.fi
}

\begin{abstract}
The construction industry needs new tools and approaches to develop their business processes. The objective of this paper is to introduce a new framework for re-engineering logistics chains in the construction industry. The re-engineering process is based on co-operation between construction firms and material suppliers. Designers and subcontractors also participate when necessary.

Two tools are introduced as a part of the framework. These tools measure the effectiviness of information and material flows. The objective of the tools is to identify opportunities to improve logistics chains of different construction materials. With these tools logistics chains can be benchmarked to find out best practices and improvement potentials of the firms.

One objective of the paper is to emphasize the importance of a process view of construction logistics. The focus is on material and information flows between designers, material suppliers and construction firms.
\end{abstract}

\section{Keywords}

Logistics chains, measuring tools, re-engineering process, construction industry

\section{INTRODUCTION}

Construction projects typically involve many actors: an owner, an architect, design offices, a main contractor, subcontractors and material suppliers. In addition, the products (buildings) are usually unique. The construction site organisations and other actors change project by project. 
In this situation, many people in construction firms think that one of the main problems is the lack of repetitiveness and this is why the coordination of material and information flows is difficult. That assumption is wrong. What people can't see is that the construction industry is a typical "one-of the kind" -production industry (Burbidge 1993). Products are different project by project, but work and material delivery processes are almost the same.

Material costs are over $50 \%$ of the building costs (Asplund and Danielson 1991). Therefore, material deliveries play an important role in constuction processes. Materials can be grouped into two categories: a-class materials that are customized materials (design to order) and b-class materials that are standard materials (make to order or make to stock). At the moment, there are big problems in the both material groups. Design changes, timing, shortages, handling and storing, damages, waste and packaging are the main problems.

At the same time, there are many challenges that construction industry should respond to. In competitive industries firms always have cost saving requirements. This is especially so when the economy is in a recession. Cost efficiency is not enough for competitiveness. Profitable construction firms increasingly have to be also time-based competitive. That means shorter delivery times. Re-engineering the logistics processes is needed if the construction industry wants to respond to these challenges.

This article offers some new tools and approaches to develop business processes in the construction industry. In the next chapter, a new framework for the re-engineering process is introduced with two measuring tools. The framework and the tools are applied in chapter three and the key results of a case study is described. More general results are presented in chapter four and conclusions are made in chapter five.

\section{SOLUTION METHODOLOGY AND THE MEASURING TOOLS}

\subsection{The new framework for the re-engineering process}

The new framework for the re-engineering process is based on a process view and cooperation of the firms operating in delivery chains. Because of a lack of partnership thinking, re-engineering process typically requires a development project. The project involves a construction firm as well as a material supplier. The reason is that the measuring and reengineering process is carried out material by material.

The best results can be reached if the whole consortium of material suppliers and construction firms develop their processes at the same time. This way benchmarking can be used and firms are more active and curious to get results.

There are five key steps in the re-engineering process:

1. Identifying delivery processes and measuring the current performance

2. Benchmarking current practices

3. Re-engineering a new ideal model

4. Testing new practices on pilot projects

5. Putting new tested practices into use 
The first step in the re-engineering process is to evaluate the current performance and practices. For that purpose, some example construction sites are chosen and the material deliveries of the chosen material groups are analyzed by the measuring tools. The more there are example sites, the better possibilities there are to find out different practices and to benchmark them. The idea is to search for present best practices and improvement potentials.

After analyzing and benchmarking current practices the project continues in the development groups. These groups re-engineer the logistics chains further by creating cost saving solutions to the problems that were evaluated in the first step.

Both material suppliers and construction firms participate in these development groups, as well as a reseacher. The best experts are those who are working with material delivery processes every day. At material suppliers those are staff from sales, production and dispatching and at construction firms the best experts are purchasers and site foremen.

An important stage of the project is to test new ideas on pilot construction sites. The proposals for improvement are tested in practice and the results are evaluated. Perhaps the most difficult task is to put the best, tested practices widely into use. The systematic education and information will help to disseminate the new ideas.

\subsection{Tools for measuring costs and time}

Two measuring tools are used during the first step of the re-engineering process. The first tool is an activity and cost analysis tool and the second is an accuracy and delivery time analysis tool. The objective of the activity and cost analysis is to find out the costs of the material flow and, at the same time, to show costs of unnecessary work in the delivery chain. The objective of the accuracy and delivery time analysis is to clarify the structure of the delivery time and the accuracy of performance.

Usually the activity and cost analysis and the accuracy and delivery time analysis are implemented at the same time because the results of the analyses support each other. Therefore the material group and the sites that will be analyzed are generally the same in the both analyses.

\section{Activity and cost analysis}

The activity and cost analysis is based on the theory of activity-based costing. The principle of activity-based costing is that the operations of the company are divided into activities, which use different resources (Brimson 1991). The same method is used here for analysing activities in the logistics chains and the costs of these activities. The activity and cost analysis focuses on material flows.

The first step of the activity and cost analysis is to identify all activities in the logistics chains. For standard materials (b-class materials), the business process starts with placing an order and ends when materials are assembled. For customized materials (a-class materials), the business process starts when architectural design starts. This stage in the analyzing process is called activity analysis. An example of the grafical representation of the activity analysis can be seen in the figure 1 . 


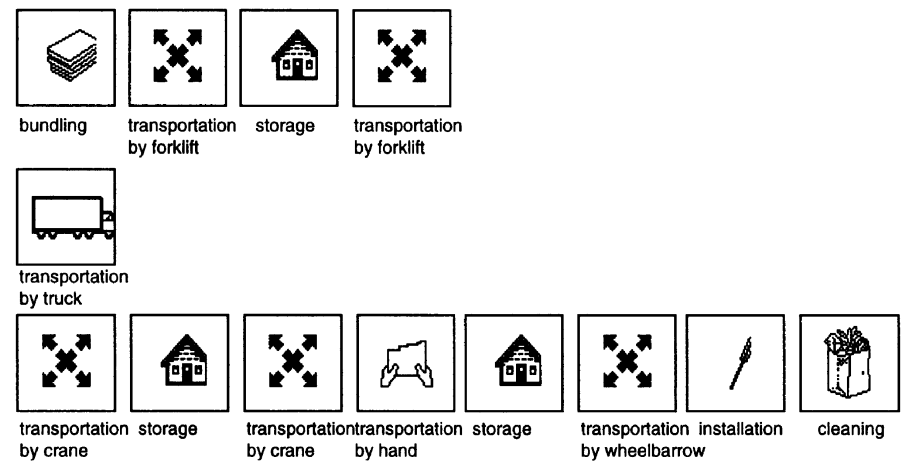

Figure 1 The logistics chain of the plasterboard deliveries on a case site.

After identifying the activities, the second step is to measure the costs of the activities. For that purpose one has to know what are the resources used by each activity. For example workers, warehouses and transport facilities are these kind of resources. It is also necessary to know what are the costs of the resources. For that purpose, a specific study has been made (Bergström J. and Gröning M. 1992). For instance, standard costs of different transportations and storages have been determined.

The costs of each activity can finally be calculated when the use of resources has been found out. After calculating the costs of each activity and the capital costs tied-up to the process, the cost structure of the logistics chain can be presented by graphs. An example is shown in the figure 2 .

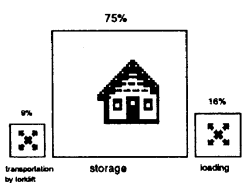

material supplier

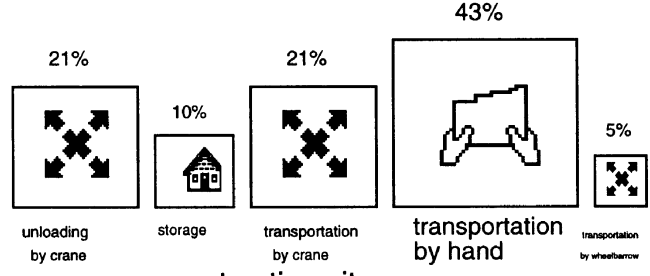

construction site

Figure 2 The logistics costs of the supplier and the case construction site. The area is correspond to the costs.

\section{Accuracy and delivery time analysis}

The accuracy and delivery time analysis has been developed to find out time lags in material and information flows. With this analysis, planned and actual timing data is gathered and showed graphically. The analysis is based on the theory of controllability engineering developed by Prof. E. Eloranta (e.g. Eloranta and Nikkola 1992). Controllability engineering aims at finding the improvement potential in business processes by using quantitative methods. The accuracy and delivery time analysis focuses especially on information flows. 
Using accuracy and delivery time analysis is very simple. First the important milestones in both the material and the information flows are defined and included to the analysis. For customized materials it is necessary to analyze also accuracy and lead time of the design process. It is essential to analyze both the planned and the actual points of time. This way accuracy of the material delivery process can be studied. The ordering day, the planned and the actual day of manufacturing and the planned and the actual delivery day are examples of these milesstones.

The second step is to collect the analysis data from different sources. To get reliable results, it is necessary to use documented data from the planned and the actual time points. Documented data can be found for example in delivery orders, production plans, construction site diaries and installation plans. If documented plans are not available, the processes are probably not planned and controlled well enough.

The most informative way to present the results of accuracy and delivery time analysis is to use graphs. This way time lags and delays in the delivery processes can easily be clarified. For example the analysis shows if a material delivery has arrived to the site many weeks before installation or if the customized material has been manufactured many weeks before the planned delivery day. Figure 3 illustrates the results of accuracy and delivery time analysis on a case site.

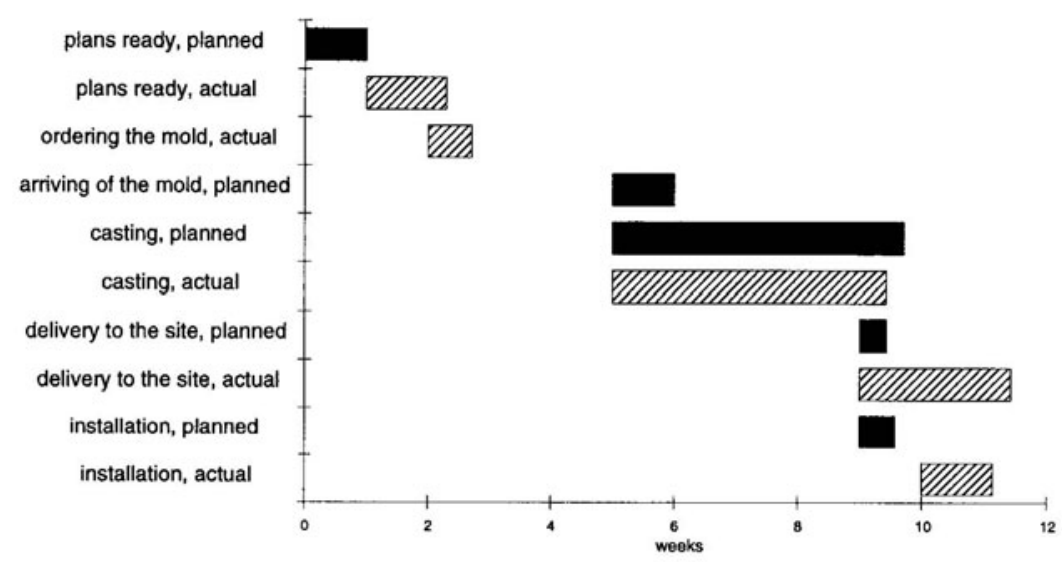

Figure 3 The structure of the delivery time of concrete elements on a case site. 


\subsection{How to measure and re-engineer plasterboard deliveries - an application example}

\section{Background}

One of the earliest re-engineering project, which used the framework introduced previously, was co-operation project between three major Finnish construction firms and a large Nordic construction material supplier. The project was carried out between the fall 1992 and the spring 1993.

Plasterboard was the material, the logistics of which was re-engineered. Plasterboard is heavy and bulky construction material which is used for interior walls. Plasterboard is typical standard b-class material which is usually made to stock.

\section{Identifying current performance}

The measuring tools were developed during this re-engineering project of plasterboard deliveries. Current performance was identified at five construction sites. One of them was a office building and the rest were residental buildings.

A typical delivery chain of the plasterboard deliveries is illustrated in the figure 1 . The logistics chain of the first case site shows that the most of the activities of the delivery chain take place at construction sites.

The figure 2 shows that also the costs of the material flow are highest at the site. In particular, several handlings and movements caused high logistics costs at the site.

Figure 4 illustrates an example of the results of the accuracy and delivery time analysis.

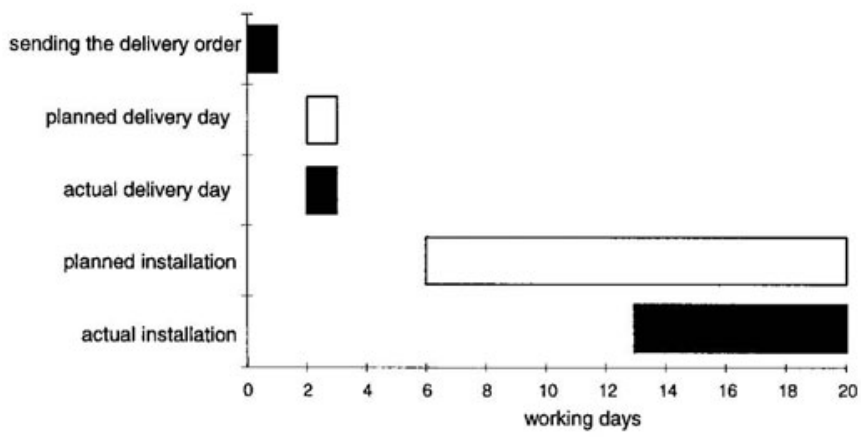

Figure 4 Delivery time and accuracy of the plasterboard delivery at the second case site.

At this second case site the delivery order was sent late and the supplier had only one day time to deliver the material. Still, the material was stored at the site more than two weeks before the installation was started. 


\section{Benchmarking current practices}

After measuring current performance, the different practices of the case sites were benchmarked using the logistics costs as a yardstick. Logistics costs were divided into three parts: logistics costs of the supplier, logistics costs of the site and the transportation costs. Figure 5 shows the logistics costs of different case sites. The logistics costs were expressed as a percentage of the purchasing price.

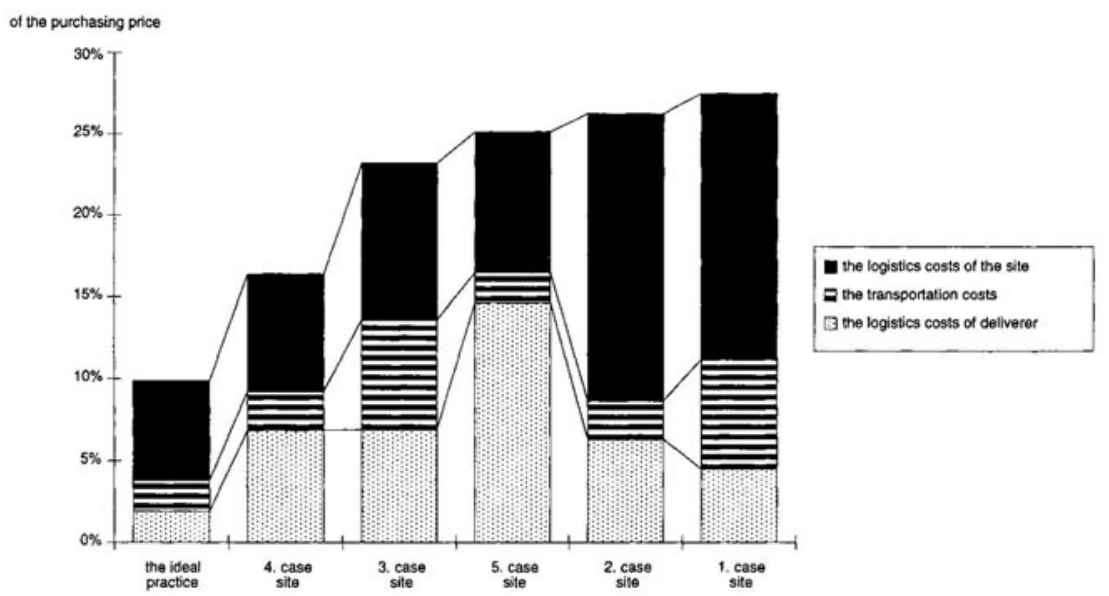

Figure 5 The logistics costs of the plasterboard deliveries on the case sites compared to the ideal practice.

There were relatively great differences in cost between the case sites. The logistics costs varied from $17 \%$ to $27 \%$ of the purchasing price. The assumption that the transportation costs would be largest cost item was proved wrong. The cost saving potential between the worst and the best practice was $10 \%$ of the purchasing price which is much more than purchasing personnel can ever get by price negotiations.

\section{Re-engineering a new ideal practice}

Figure 5 represents also the ideal practice which can be reached by combining the current best practices of each stage and by following some guidelines. The ideal practice has the most simple chain of activities. All non-value-adding activities has been removed. The guidelines to the site foreman are:

- Plan and order deliveries 1-2 weeks before need.

- Order deliveries to come to the site just in time.

- Divide purchases into smaller deliveries and plan the time points and the contents of the deliveries accurately.

- Do not order extra pieces to the installation places.

- Move the material direct to the installation place. 
If construction firms follow the principles, also the supplier can save costs by making material to order and by combining transportations of different customers.

By these means the logistics costs of ideal practice can be reached. These costs are only $10 \%$ of the purchasing price. Cost savings can be up to $17 \%$.

\section{LARGE COST SAVINGS CAN BE ACHIEVED BY CO-OPERATION}

The new framework for measuring and re-engineering logistics chains has been used in several development projects in Finland. So far plasterboard, concrete element, door, window, mortar, timber (e.g. 2x4-inch board), major appliances (refrigerators and stoves) and kitchen cabinet deliveries have been measured and re-engineered. Seven more material groups are just under development.

Activities, costs, accuracy and delivery times as well as the problems of the logistics chains have been identified and explained within these materials. Over thirty case construction sites have been studied to find out different ways to operate. Ideal models have been developed within different material delivery chains by benchmarking performances and by developing best practices further. These ideal models have been tested on several pilot construction sites.

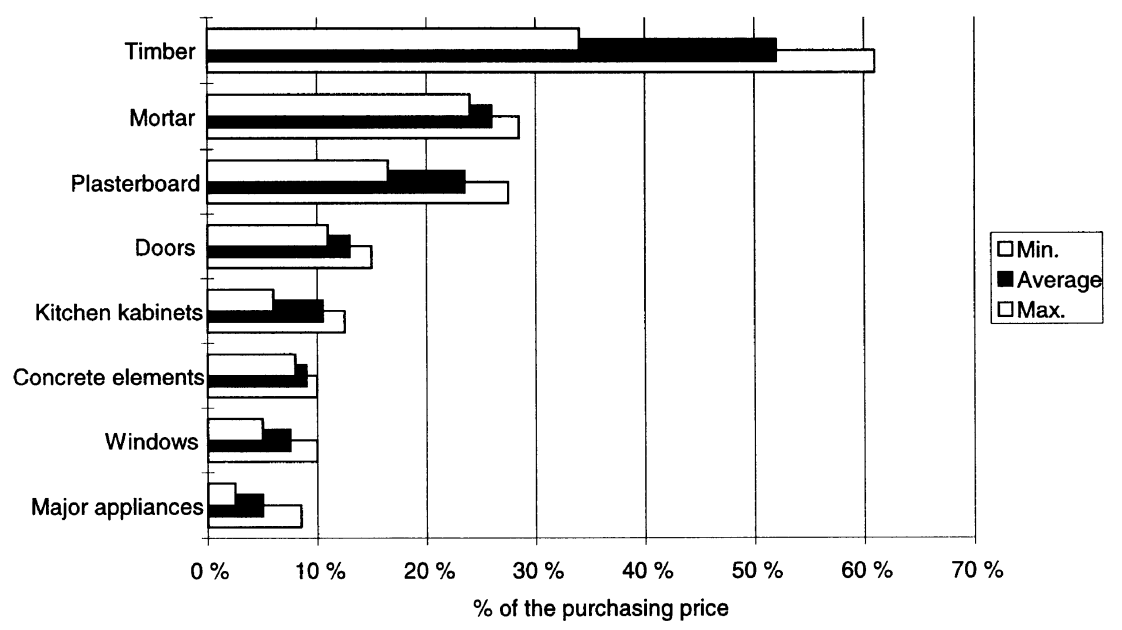

Figure 6 Minimum, average and maximum logistics costs of different material flows.

The summary of the cost analyses is illustrated in the figure 6 . The figure shows a large cost saving potential. The highest logistics costs of material flow were more than $60 \%$ of the 
purchasing price. The differences between the materials were sigfinicant; average costs of material flows varies from $5 \%$ to over $50 \%$ of the purchasing price.

Standard b-class materials usually had higher costs of the material flow than customized aclass materials. Timber, mortar and plasterboard are typical standard material while kitchen cabinets, concrete elements and windows are customized materials.

Also the differences within the material groups were great. For example the logistics costs of timber deliveries varied from $34 \%$ to over $60 \%$ of purchasing price. Expecially these differences offer a good chance to use benchmarking as a tool for development.

Several case study results show that the co-operation of suppliers and construction firms offers many improvement means. The development process is not a zero-sum game but a winwin situation.

\section{CONCLUSIONS}

The usefulness of the measuring tools depends on the type of material. The standard b-class materials have the biggest logistics costs of material flows. The logistics chain of standard materials consist of many movements and storages. A lot of money can be saved by eliminating unnecessary activities from the chains. Therefore the importance of the activity and cost analysis is emphasized in development of standard material deliveries.

The accuracy and delivery time analysis is most useful in the development of customized aclass material deliveries. Logistics chains of non-standard materials involve many actors in different companies. At least an architect, design offices, a material supplier and a contractor have to interchange a lot of information during the delivery processes of customized materials. With the accuracy and delivery time analysis, the improvement potential of information flows and co-ordination can be identified.

Although the effectiveness of the measuring tools varies, the re-engineering process is always useful by using co-operative methods. The variation of the logistics costs within the material group offers great opportunities to benchmark current practices and to find out best practices. Co-operation increases the chance for cost savings.

The division of the construction materials to a-class materials (customized) and b-class materials (standard) is used, at the moment, only when purchasing materials. However, the division is extremely useful also when managing and re-engineering material delivery processes. Problems are usually similar within these material groups. It is also possible to use similar solutions to improve these delivery chains.

\section{REFERENCES}

Asplund E. and Danielson U. (1991) Räta ut byggsvägen. Svenska byggbranschens utvecklingsfond (SBUF)

Bergström J. and Gröning M. (1992) Activity-Based cost in the logistics of construction industry (in Finnish), Helsinki University of Technology

Brimson J.A. (1991) Activity Accounting; an Activity-Based Costing Approach. John Wiley \& Sons Inc., New York 
Burbidge J.L. and Falster P. (1993) Reducing delivery times for OKP products. Production planning and control, vol. 4, no 1, pp.77-83

Eloranta E. and Nikkola J. (1992) Economic Aspects in Production Management. Computers in Industry, vol.19, pp. 51-64

\section{BIOGRAPHY}

Tutu Wegelius-Lehtonen is a researcher with the IIA Research center at the Helsinki University of Technology in Finland. Her current research focuses on the logistics of the construction industry. She develops new methods and tools that support co-operative reengineering projects of business processes. At the moment, she is working with several Finnish construction companies and material suppliers to improve their logistics chains. She received her MSc in industrial economics from the Helsinki University of Technology. 